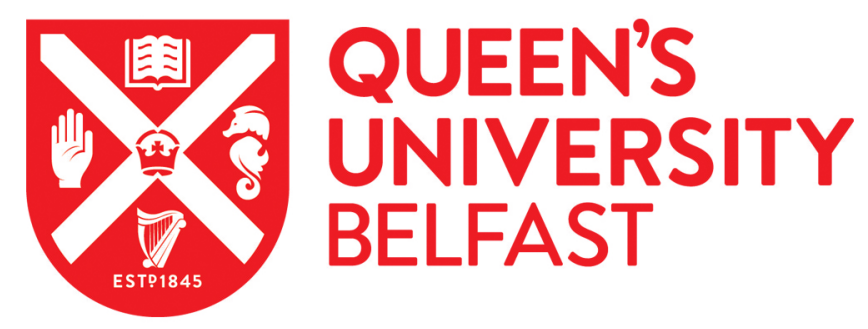

\title{
Respective contribution of conventional risk factors and antihypertensive treatment to stabel angina pectoris and acute coronary syndrome as the first presentation of coronary heart disease the PRIME study
}

\author{
Canoui Poitrine, F., Luc, G., Juhan Vague, I., \& Kee, F. (2009). Respective contribution of conventional risk \\ factors and antihypertensive treatment to stabel angina pectoris and acute coronary syndrome as the first \\ presentation of coronary heart disease the PRIME study. European Journal of Cardiovascular Prevention and \\ Rehabilitation, 16(5), 550-555. https://doi.org/10.1097/HJR.0b013e32832c88d1 \\ Published in: \\ European Journal of Cardiovascular Prevention and Rehabilitation
}

Queen's University Belfast - Research Portal:

Link to publication record in Queen's University Belfast Research Portal

\begin{abstract}
General rights
Copyright for the publications made accessible via the Queen's University Belfast Research Portal is retained by the author(s) and / or other copyright owners and it is a condition of accessing these publications that users recognise and abide by the legal requirements associated
\end{abstract} with these rights.

Take down policy

The Research Portal is Queen's institutional repository that provides access to Queen's research output. Every effort has been made to ensure that content in the Research Portal does not infringe any person's rights, or applicable UK laws. If you discover content in the Research Portal that you believe breaches copyright or violates any law, please contact openaccess@qub.ac.uk. 


\section{Respective contribution of conventional risk factors and antihypertensive treatment to stable angina pectoris and acute coronary syndrome as the first presentation of coronary heart disease: the PRIME Study} Florence Canoui-Poitrine ${ }^{\mathrm{a}, \mathrm{b}}$, Gerald Luc ${ }^{\mathrm{c}}$, Irène Juhan-Vague ${ }^{\mathrm{d}}$, Pierre-Emmanuel Morange ${ }^{d}$, Dominique Arveiler ${ }^{e}$, Jean Ferrieres ${ }^{f}$, Philippe Amouyel ${ }^{g}$, Annie Bingham ${ }^{\mathrm{a}}$, Michèle Montaye ${ }^{\mathrm{g}}$, Jean-Bernard Ruidavets ${ }^{f}$, Bernadette Haas ${ }^{\mathrm{e}}$, Alun Evansi, Pierre Ducimetiere ${ }^{\mathrm{h}}$ and Jean-Philippe Empana ${ }^{\text {a }}$; on behalf of the PRIME Study Group*

aINSERM, U970, Paris Cardiovascular Research Centre (PAARC), Université Paris V, Paris, b Hospices Civils de Lyon, Pôle Information Medicale Evaluation Recherche, Université Lyon 1, Université de Lyon, Lyon, 'Department of Atherosclerosis, INSERM, U545, Lille, Institut Pasteur de Lille, Lille; and Faculté de Médecine, and Université Lille Nord de France, Lille, 'Laboratory of Haematology, INSERM, U626, La

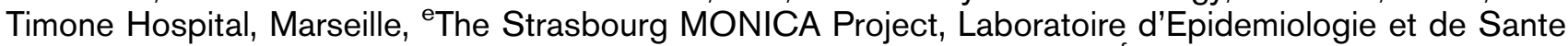
Publique, EA 3430, Strasbourg, and Universite de Strasbourg, Strasbourg, ${ }^{\mathrm{f}}$ The Toulouse MONICA Project, INSERM U558, Département d'Epidémiologie, Université Paul Sabatier, Toulouse Purpan, Toulouse, ${ }^{9}$ The Lille MONICA Project, INSERM, U744, Lille, and Institut Pasteur de Lille, and Université Lille Nord de France, Lille, hIFR 69-Paris Sud University, Villejuif, France and 'Department of Epidemiology; and Public Health and the UKCRC Centre of Excellence for Public Health, Queen's University, Belfast, Northern Ireland

Received 9 December 2008 Accepted 3 April 2009

Objective To test whether conventional risk factors and antihypertensive treatment were more predictive of stable angina (SA) than acute coronary syndrome (ACS) as the first presentation of coronary heart disease (CHD).

Design We used data from the PRIME Study (Prospective Epidemiological Study of Myocardial Infarction), a prospective cohort of 9758 asymptomatic middle-aged men recruited from WHO MONICA centers in Northern Ireland and France between 1991 and 1993. SA and ACS events were registered during 5 years of follow-up.

Methods Hazard ratios (HRs) of each risk factor measured at baseline for SA and ACS events were assessed using separate Cox proportional hazard models. Difference between HRs was estimated by the bootstrap method.

Results After 5 years of follow-up, there were 114 SA and 178 ACS as the first presentation of CHD. Diastolic blood pressure [adjusted HRs for 1 standard deviation increase $=1.34$; 95\% confidence interval (Cl): $1.17-1.54$ vs. $1.04 ; 95 \% \mathrm{Cl}$ : 0.87-1.25; $P$ for comparison between HRs $=0.012$ ], and possibly cigarette smoking over or equal to 20 pack-years (adjusted HR=2.07; 95\% Cl: $1.43-2.99$ vs. $1.29 ; 95 \% \mathrm{Cl}: 0.83-2.01 ; P$ for comparison between HRs $=0.062$ ) were more predictive of ACS than SA, whereas this was the opposite for antihypertensive treatment (adjusted HR=2.18; 95\% Cl: 1.39-3.41 for SA vs. 1.28; $95 \% \mathrm{Cl}$ : $0.85-1.93$ for ACS, $P$ for comparison between HRs $=0.049$ ).

Conclusion The present data support that SA and ACS, as the first presentation of CHD, may not share exactly the same determinants. Eur J Cardiovasc Prev Rehabil 16:550-555 @ 2009 The European Society of Cardiology

European Journal of Cardiovascular Prevention and Rehabilitation 2009, 16:550-555

Keywords: acute coronary syndrome, epidemiology, risk factors, stable angina

Correspondence to Dr Florence Canouï-Poitrine, MD, Hospices Civils de Lyon, Pole IMER, 162 Avenue Lacassagne, 69424 Lyon Cedex 03, France

Tel: + 334721157 59; fax: + 33472115720 ;

e-mail: florence.canoui-poitrine@chu-lyon.fr

*The PRIME Study is organized under an agreement between INSERM and the Merck, Sharpe and Dohme-Chibret Laboratory, with a few other participating laboratories; a list immediately preceded the References.

\section{Introduction}

First, clinical presentation of coronary heart disease (CHD) can vary from stable angina (SA) to acute coronary syndrome (ACS) [1]. In most earlier population studies investigating risk factors for CHD, coronary 
events were grouped together on the assumption that they all shared the same risk factors [2-4]. However, histopathological and echographic data indicate that ACS is triggered by the rupture of an atherosclerotic plaque with subsequent thrombosis formation contrary to SA $[5,6]$. This may suggest that ACS and SA may not share exactly the same risk factors. Only a few population-based studies have explored and suggested that the association of conventional risk factors with the various CHD phenotypes may differ [7-9]. However, these studies were conducted in the late 1970s, which included angina pectoris as defined by pain symptoms only and did not provide formal statistical comparison between risk estimates.

Therefore, using prospective data from the PRIME Study (Prospective Epidemiological Study of Myocardial Infarction), we have compared the association of conventional CHD risk factors and antihypertensive treatment use with well-characterized SA and ACS events as the first presentation of CHD.

\section{Methods}

\section{Study population}

Details on recruitment, baseline examination, and followup of the PRIME Study have been described earlier [10]. Briefly, the PRIME Study is a multicenter prospective cohort of 9758 men aged 50-59 years and without personal history of CHD, who were recruited in the framework of WHO MONICA centers in Lille, Strasbourg and Toulouse in France and Belfast in Northern Ireland between 1991 and 1993. The protocol was approved by the Institutional Review Board of the Hospital Broussais, Paris, France. Informed consent was obtained for each patient who agreed to participate in the PRIME Study.

\section{Baseline examination}

\section{General characteristics}

Patients who agreed to participate in the study were given a morning appointment and asked to fast for at least $12 \mathrm{~h}$ before their examination. A full description of clinical and laboratory measurements has been published earlier [10]. Parental history of early myocardial infarction (MI) was defined as an MI that occurred before 55 years of age for the father and before 65 years age for the mother. Diabetes was defined by the current intake of oral hypoglycemic treatment or insulin. Blood pressure was measured twice in the sitting position with the same automatic device (Spengler SP9; Spengler, Cachan, France). Pulse pressure was defined as systolic blood pressure minus diastolic blood pressure. A 12-lead electrocardiogram was also recorded.

\section{Biologic measurements}

A subset of biological measurements was performed in the entire cohort at baseline. Plasma lipids analyses were centralized (SERLIA INSERM U325, Institut Pasteur de Lille, France). Total cholesterol was measured by enzymatic methods using commercial kits in an automatic analyzer (Boehringer, Mannheim, Germany). Highdensity lipoprotein (HDL)-cholesterol was determined after the precipitation of apolipoprotein B by enzymatic methods (Boehringer). Low-density lipoprotein (LDL)cholesterol was calculated according to the Friedewald formula for triglycerides $\leq 4.5 \mathrm{~g} / \mathrm{l}$.

\section{Follow-up and ascertainment of cases}

During the 5-year follow-up, participants were contacted annually by letter and asked to complete a clinical event questionnaire. For all the participants reporting a possible event, clinical information was sought directly from the hospital or general practitioner records. All details of electrocardiograms, hospital admissions, enzymes, surgical intervention, angioplasty, treatments, etc. were collected. Whenever possible, circumstances of death were obtained from the practitioner or the family. In the few cases where the circumstances surrounding the death were not available from the practitioner or the family, death certificates were checked for supporting clinical and postmortem information on cause of death. All coronary events were validated by an independent medical committee.

SA was defined by the presence of chest pain on exertion and one of the following criteria: (i) angiographic stenosis over 50\%; (ii) a positive scintigraphy (if no angiographic data); and (iii) a positive exercise stress (if no angiographic or scintigraphy data). Unstable angina was defined as a crescendo pain or chest pain at rest, with either enzyme changes lower than twice the upper limit or electrical changes at rest but without MI and no evidence of a noncoronary cause in the clinical history, and one of the angiographic or scintigraphic criteria defined above. In the absence of enzyme or electrical data, the diagnosis was not upheld.

MI was defined by one of the following set of conditions: (i) new diagnostic $Q$ wave or other fresh typical electrocardiographic signs of necrosis; (ii) typical or atypical pain symptoms and new (or increased) ischemia and myocardial enzyme levels higher than twice the upper limit; and (iii) post-mortem evidence of fresh MI or thrombosis. As only MIs that led to hospitalization were searched for during follow-up, silent MIs were not individually considered in this study. Coronary death was defined as death with a documented coronary event.

After 5 years of follow-up, the CHD event status was available for $98.8 \%$ of the cohort and 317 incident CHD events were validated. However, of these 317, 292 well-characterized incident events were included for the analysis and 25 suspected coronary deaths were excluded, as the coronary event leading to death was not documented. For the five men who developed successive CHD events during follow-up, only the first, SA in the 
present situation, was considered for the analysis. Taken together, two diagnosis categories were constructed: SA and ACS including unstable angina and MI (fatal and nonfatal).

\section{Statistical analysis}

The baseline characteristics of men who developed SA, ACS, and of those who remained free of CHD during follow-up were compared using analysis of variance and Pearson's $\chi^{2}$ test for continuous and categorical variables, respectively. Hazard ratios (HRs) for SA and ACS associated with each risk factor were estimated in separate Cox proportional hazard models; HRs of continuous variables were calculated for 1 standard deviation (SD) increase estimated in the overall cohort. Adjustment was made for baseline covariates, including the study centers; age; parental history of early MI; cigarette smoking; alcohol intake; body mass index; systolic, diastolic, or pulse blood pressure; diabetes, HDL and LDL-cholesterol, and antihypertensive treatment use. To compare the HRs of a given risk factor for SA or ACS, we performed bootstrap analyses. We chose a random sample of the same size as the original data set and within this set, we calculated the HR of each risk factor for SA and ACS, and the difference in the corresponding regression coefficient as well. We repeated this process 1000 times, each time on a random sample chosen with replacement, ordered differences between regression coefficients [11]. A onesided test with a $P$ value of less than 0.05 was used as the cut-off value of statistical significance for the difference between regression coefficients. Analyses were performed using Stata software 9.1 Version (StataCorp, College Station, Texas, USA).

\section{Results}

Incidence of stable angina and acute coronary syndrome Among the 9758 men who were free of CHD at baseline, 114 subsequently developed a first SA and 178 a first ACS event (40 unstable angina events and 138 MIs) over 5 years of follow-up, respectively. This yielded an incidence rate [95\% confidence interval (CI)] of 2.39 (1.95-2.83) and $4.95(4.22-5.68)$ per 1000 person-years for SA and ACS, respectively.

\section{Baseline characteristics of the cohort}

The baseline characteristics in men who developed SA, ACS, and in those who remained free of CHD during the follow-up are described in Table 1 . As expected, the patients who developed CHD event (SA or ACS) had a higher CHD risk profile in comparison with the reference group. More specifically, cigarette smoking and mean diastolic blood pressure (in treated and in untreated men) were higher in those with ACS compared to those with SA. Instead, mean pulse pressure, mean systolic

Table 1 Baseline characteristics of the cohort according to first coronary event developed after 5 years of follow-up: the PRIME Study

\begin{tabular}{|c|c|c|c|c|}
\hline & $\begin{array}{l}\text { No CHD, } \\
n=9441\end{array}$ & $\begin{array}{l}\text { Stable angina, } \\
\quad n=114\end{array}$ & $\begin{array}{l}\text { Acute coronary syndrome, } \\
\qquad n=178\end{array}$ & $P^{\mathrm{a}}$ \\
\hline Age (years) & $54.8(2.9)$ & $55.4(2.9)$ & $55.3(2.9)$ & 0.019 \\
\hline Parental history of early MI & $10.0(945)$ & $18.4(21)$ & $20.2(36)$ & $<0.001$ \\
\hline Nonsmokers & $37.6(3529)$ & $31.3(35)$ & $25.4(45)$ & $<0.001$ \\
\hline$<20$ packs-years & $28.4(2667)$ & $26.8(30)$ & $22.0(39)$ & \\
\hline$\geq 20$ packs-years & 33.9 (3184) & $42.0(47)$ & $52.5(93)$ & \\
\hline Alcohol intake (g/day) & $37.9(38.2)$ & $31.7(36.5)$ & $34.8(47.8)$ & 0.13 \\
\hline Body mass index $\left(\mathrm{kg} / \mathrm{m}^{2}\right)$ & $26.5(3.43)$ & $27.5(3.40)$ & $27.2(3.77)$ & $<0.001$ \\
\hline \multicolumn{5}{|l|}{$\mathrm{SBP}(\mathrm{mmHg})$} \\
\hline Without treatment & $131.5(17.6)$ & $138.4(21.0)$ & $138.8(21.2)$ & $<0.001$ \\
\hline With treatment & $146.4(20.5)$ & $151.0(24.0)$ & $148.8(18.7)$ & 0.38 \\
\hline \multicolumn{5}{|l|}{$\mathrm{DBP}(\mathrm{mmHg})$} \\
\hline Without treatment & $82.6(11.1)$ & $84.4(13.5)$ & $86.4(11.1)$ & $<0.001$ \\
\hline With treatment & $90.4(12.9)$ & 89.7 (13.3) & $92.7(10.1)$ & 0.53 \\
\hline \multicolumn{5}{|l|}{ Pulse pressure $(\mathrm{mmHg})$} \\
\hline Without treatment & $48.8(12.8)$ & $54.0(16.0)$ & $52.4(16.6)$ & $<0.001$ \\
\hline With treatment & $56.0(15.5)$ & $61.3(17.3)$ & $56.0(15.6)$ & 0.28 \\
\hline Diabetes & $2.9(272)$ & $4.4(5)$ & $5.6(10)$ & 0.063 \\
\hline LDL-cholesterol (g/l) & $1.44(0.34)$ & $1.60(0.36)$ & $1.55(0.31)$ & $<0.001$ \\
\hline HDL-cholesterol (g/l) & $0.49(0.13)$ & $0.45(0.12)$ & $0.45(0.13)$ & $<0.001$ \\
\hline Antihypertensive treatment & $12.9(1217)$ & $28.1(32)$ & $19.7(35)$ & $<0.001$ \\
\hline$\beta$-blockers & $5.1(481)$ & $14.0(16)$ & $9.0(16)$ & - \\
\hline ACE inhibitors & $4.8(449)$ & $7.0(8)$ & $6.7(12)$ & - \\
\hline Calcium channel blockers & $2.6(249)$ & $8.9(10)$ & $5.1(9)$ & - \\
\hline Diuretics & 4.2 (395) & $3.5(4)$ & $5.1(9)$ & - \\
\hline Others & $1.4(134)$ & $1.8(2)$ & 1.7 (3) & - \\
\hline Lipid-lowering treatment & $8.5(798)$ & $10.5(12)$ & $10.1(18)$ & 0.54 \\
\hline Fibrates & $5.6(531)$ & $5.3(6)$ & $6.7(12)$ & - \\
\hline Statins & $2.8(267)$ & $5.3(6)$ & $3.4(6)$ & - \\
\hline Aspirin & $3.4(316)$ & $1.8(2)$ & $2.3(4)$ & - \\
\hline
\end{tabular}

Data are expressed as mean (SD) and \% $(n)$ for continuous and categorical variables, respectively. ACE, angiotensin-converting enzyme; CHD, coronary heart disease; DBP, diastolic blood pressure; HDL, high-density lipoprotein; LDL, low-density lipoprotein; MI, myocardial infarction; PRIME Study, Prospective Epidemiological Study of Myocardial Infarction; SBP, systolic blood pressure. ${ }^{a} P$ values for comparison among the three groups: ANOVA and $\chi^{2}$ or Fischer's exact test for continuous and categorical variables, respectively. 
blood pressure (in treated men), and antihypertensive treatment use were higher in men who experienced SA than in those who developed ACS. Lipid-lowering treatment use was not different between the two groups.

\section{Predictors of first coronary heart disease event}

Table 2 compares the adjusted HRs of each risk factor for SA and ACS. Parental history of early MI (borderline statistical significance), systolic blood pressure, HDL and LDL-cholesterol, were equally predictive of SA and ACS. Pulse pressure tended to be more predictive of SA (HR for $1 \mathrm{SD}$ increase $=1.35 ; 95 \%$ CI: $1.15-1.58$ ) than ACS (HR for 1SD increase $=1.18$; 95\% CI: 1.02-1.36), although the difference between the two HRs was not statistically significant $(P=0.12)$. In contrast, diastolic blood pressure and cigarette smoking $\geq 20$ pack-years were associated with ACS but not with SA. Difference between HRs was statistically significant for diastolic blood pressure $(P=0.012)$, and borderline significant for cigarette smoking $(P=0.062)$. Antihypertensive treatment use was associated with SA but not with ACS, and difference between HRs was statistically significant $(P=0.049)$.

\section{Discussion}

In this prospective study of initially asymptomatic middle-aged men, elevated diastolic blood pressure and

\begin{tabular}{|c|c|c|c|}
\hline & $\begin{array}{l}\text { Stable angina, } \\
\quad n=114\end{array}$ & $\begin{array}{l}\text { Acute coronary } \\
\text { syndrome } \\
n=178\end{array}$ & $P^{\mathrm{a}}$ \\
\hline Age (years) & $1.04(0.97-1.11)$ & $1.05(1.00-1.11)$ & 0.35 \\
\hline \multicolumn{4}{|l|}{ Parental history of early MI } \\
\hline No & 1.00 & 1.00 & \\
\hline Yes & $1.54(0.94-2.52)$ & $1.60(1.07-2.40)$ & 0.44 \\
\hline \multicolumn{4}{|c|}{ Cigarette smoking (pack-years) } \\
\hline Nonsmokers & 1.00 & 1.00 & \\
\hline$<20$ & $1.21(0.74-1.96)$ & $1.26(0.82-1.95)$ & 0.45 \\
\hline$\geq 20$ & $1.29(0.83-2.01)$ & $2.07(1.43-2.99)$ & 0.062 \\
\hline Alcohol consumption (g/day) & $0.93(0.75-1.16)$ & $0.98(0.83-1.15)$ & 0.38 \\
\hline Body mass index $\left(\mathrm{kg} / \mathrm{m}^{2}\right)$ & $1.08(0.89-1.32)$ & $0.97(0.82-1.14)$ & 0.17 \\
\hline $\mathrm{SBP}(\mathrm{mmHg})$ & $1.29(1.09-1.52)$ & $1.34(1.17-1.54)$ & 0.36 \\
\hline $\mathrm{DBP}(\mathrm{mmHg})$ & $1.04(0.87-1.25)$ & $1.34(1.17-1.54)$ & 0.012 \\
\hline Pulse pressure $(\mathrm{mmHg})$ & $1.35(1.15-1.58)$ & $1.18(1.02-1.36)$ & 0.12 \\
\hline \multicolumn{4}{|l|}{ Diabetes } \\
\hline No & 1.00 & 1.00 & \\
\hline Yes & $0.96(0.35-2.65)$ & $1.63(0.82-3.24)$ & 0.19 \\
\hline HDL-cholesterol (g/l) & $0.74(0.58-0.94)$ & $0.76(0.63-0.92)$ & 0.40 \\
\hline LDL-cholesterol (g/l) & $1.50(1.26-1.79)$ & $1.33(1.15-1.54)$ & 0.15 \\
\hline \multicolumn{4}{|l|}{ Antihypertensive treatment } \\
\hline No & 1.00 & 1.00 & \\
\hline Yes & $2.18(1.39-3.41)$ & $1.28(0.85-1.93)$ & 0.049 \\
\hline
\end{tabular}

HRs were estimated by separate Cox proportional hazard models adjusted for study centres, age, parental history of early $\mathrm{Ml}$, cigarette smoking, alcoho intake, body mass index, diabetes, SBP (or DBP or pulse pressure), HDL and LDL-cholesterol, and antihypertensive treatment; $\mathrm{HRs}$ for continuous variables are given for $1 \mathrm{SD}$ except for age (1 year). DBP, diastolic blood pressure; HDL, highdensity lipoprotein; HRs, hazard ratios; LDL, low-density lipoprotein; MI, myocardial infarction; PRIME Study, Prospective Epidemiological Study of Myocardial Infarction; SBP, systolic blood pressure. ${ }^{a} P$ values for comparisons between HRs were assessed using bootstrap method with a one-sided test. possibly cigarette smoking $\geq 20$ pack-years were more predictive of ACS than SA as the first presentation of CHD over 5 years of follow-up. In contrast, the use of antihypertensive treatment was more likely associated with SA than ACS.

Population incidence rate estimates of the different phenotypes of CHD, including ACS and SA, are currently lacking. One Danish cohort considered hospitalized ACS between 2000 and 2002 in participants aged 30-69 years [12]. In the subgroup of men aged 50-59 years, incidence rate of ACS was 4.7 per 1000 person-years, which is of the same order of magnitude as the 4.95 per 1000 personyears reported in the PRIME Study. Conversely, in one recent Finnish study of patients aged 45-89, incidence rate of SA in the subgroup of men aged 55-64 years was three to five times higher than that observed in the PRIME Study [13]. In that study, however, the prevalence of cardiovascular comorbidities, including heart failure, was particularly high (9\%).

In the few earlier studies that had investigated risk factors for CHD phenotypes, SA was mostly defined on the basis of self-reported pain symptom only [7-9], whereas in the PRIME Study, more stringent criteria, including biological, invasive (angiography), and noninvasive tests (stress test), were additionally used, limiting the classification bias on SA. Besides, earlier studies were mostly conducted in the late 1970 s, when risk factor levels were higher and effective cardiovascular therapies less available, than at the time of the PRIME baseline examination. Nevertheless, we considered ACS as a homogeneous group, whereas the results of the EuroHeart Survey suggest that ACS with and without ST elevation at hospital presentation may not share the same determinants [14]. Unfortunately, we were not able to perform reliably such stratified analysis.

The current findings that heavy smoking tended to be more predictive of ACS than SA, is consistent with the results of three prior population-based prospective studies [7-9]. It is also consistent with experimental evidence showing that smoking enhances the risk of plaque rupture of a lipid-rich, thin-capped atheroma in men [5]. Moreover, exposure to cigarette smoking has been shown to promote the initiation and the propagation of thrombus formation and to limit its effective dissolution $[15,16]$.

We observed that elevated diastolic blood pressure was associated with ACS but not with SA, consistent with some physiopathological arguments. In addition to its chronic effect on atherosclerosis development [17], elevated blood pressure has acute effect in triggering acute plaque disruption by inducing mechanical stress on the arterial wall $[5,18]$. Elevated blood pressure has 
also been associated with impaired fibrinolytic activity and may thereby reduce the chance of spontaneous thrombolysis in case of an atherothrombotic event [19]. Nonetheless, that diastolic but not systolic blood pressure was preferentially associated with ACS was unclear, although this was reported in one earlier longitudinal study [9]. Pulse pressure was previously reported as an independent risk factor of cardiovascular mortality and MI in middle-aged men [20-22]. However, to the best of our knowledge, its association with SA has not yet been evaluated in observational studies. In this study, pulse pressure was predictive of both SA and ACS, with a higher magnitude for the former. We found that antihypertensive treatment was associated with a higher relative risk of SA than ACS, which is concordant with the protective effect of antihypertensive treatment toward the risk of unstable, higher-risk clinical presentations of CHD. In a recent retrospective observational study conducted in participants of a large health care delivery system in Northern Carolina, recent use of $\beta$-blockers and statin treatment was predictive of first SA as defined clinically (natural history of pain symptom) but not first MI [23]. We have currently complemented these prior findings on antihypertensive treatment on a prospective basis, in a European population, using more specific criteria for the definition of SA. We did not perform analysis by subclass of antihypertensive treatment, as there were very few events in each subclass.

What might be the implications of our findings for primary prevention of CHD? The incidence rate of CHD have been declining for the past 20 years, and a large part of this decline has been attributable to a better control of cardiovascular risk factors and of smoking in particular (especially in men) $[24,25]$. Therefore, that smoking status (and diastolic blood pressure) was more predictive of ACS than SA in this study raised the hypothesis that the observed decrease in CHD incidence concerned especially unstable, higher-risk clinical presentations of CHD.

The reported results should be interpreted with some limitations in mind. We may have lacked adequate power, suggesting that identified differential associations may have been underestimated, and that true but smaller differential association may not have been detected. No interim examinations were conducted here so that change in risk factor levels and in therapy during follow-up was not controlled for. Finally, the transportability of the current results in women and in elderly populations should be evaluated.

In conclusion, this prospective study suggests that elevated diastolic blood pressure and possibly cigarette smoking may be more predictive of ACS than SA as a first presentation of CHD. In contrast, antihypertensive treatment use may be more likely associated with SA than
ACS. Taken together, these findings support the hypothesis that SA and ACS as first manifestation of CHD may not share all the same determinants.

\section{Acknowledgements}

The authors thank the following organizations which allowed the recruitment of the PRIME participants: the health screening centers organized by the Social Security of Lille (Institut Pasteur), Strasbourg, Toulouse and Tourcoing; Occupational Medicine Services of Haute-Garonne, the Urban Community of Strasbourg; the Association Inter-entreprises des Services Médicaux du Travail de Lille et environs; the Comité pour le Développement de la Médecine du Travail; the Mutuelle Générale des PTT du Bas-Rhin; the Laboratoire d'Analyses de l'Institut de Chimie Biologique de la Faculté de Médecine de Strasbourg; the Department of Health (NI); and the Northern Ireland Chest Heart and Stroke Association. They also thank the members of the validation committee: Professor L. Guize, Dr C. Morrison, Dr M-T. Guillanneuf, Professor M. Giroud; and the Alliance Partnership Programme for its financial support. The PRIME Study was funded by INSERM and the Merck, Sharpe and Dohme-Chibret Laboratories. The authors were completely responsible for all the aspects of the study design; in the collection, analysis and the interpretation of the data; in the writing of the report; and in the decision to submit the article for publication.

Conflicts of interest: none declared.

\section{Appendix}

The Strasbourg MONICA Project, Laboratoire d'Epidemiologie et de Sante Publique, EA1801, Strasbourg, F-67085, France; Universite Louis Pasteur, Faculte de Medecine, Strasbourg, F-67085, France (D. Arveiler, B. Haas).

The Toulouse MONICA Project, INSERM U558; Département d'Epidemiologie, Universite Paul Sabatier, Toulouse Purpan, Toulouse, France (J. Ferrières, JB. Ruidavets).

The Lille MONICA Project, INSERM, U744, Lille, France; Institut Pasteur de Lille, Lille, France; Université de Lille 2, Lille, France (P. Amouyel, M. Montaye).

The Department of Epidemiology and Public Health, Queen's University, Belfast, Northern Ireland (A. Evans, J. Yarnell, F. Kee).

The Department of Atherosclerosis, INSERM, U545, Lille; Institut Pasteur de Lille, Lille; Université de Lille 2, Lille, France (G. Luc, J.M. Bard).

The Laboratory of Haematology, INSERM, U626, Marseille, Hôpital La Timone, Marseille, France (I. Juhan-Vague, P Morange). 
The Laboratory of Endocrinology, INSERM U563, Toulouse, France (B. Perret).

The Vitamin Research Unit, The University of Bern, Bern, Switzerland (F. Gey).

The Nutrition and Metabolism Group, Centre for Clinical and Population Sciences, Queen's University Belfast, Northern Ireland (J. Woodside, I. Young).

The DNA Bank, INSERM U525, Paris, France (F. Cambien).

The Coordinating Center, INSERM, Unit 909, Villejuif, F-94807, France; University Paris-Sud, Faculty of Medicine, Villejuif F-94807, France (P. Ducimetiere, A. Bingham).

\section{References}

1 Theroux P, Fuster V. Acute coronary syndromes: unstable angina and non-Q-wave myocardial infarction. Circulation 1998; 97:1195-1206.

2 Jousilahti P, Vartiainen E, Tuomilehto J, Puska P. Sex, age, cardiovascular risk factors, and coronary heart disease: a prospective follow-up study of 14786 middle-aged men and womenin Finland. Circulation 1999; 99:1165-1172.

3 Folsom AR, Nieto FJ, McGovern PG, Tsai MY, Malinow MR, Eckfeldt JH, et al. Prospective study of coronary heart disease incidence in relation to fasting total homocysteine, related genetic polymorphisms, and B vitamins: the Atherosclerosis Risk in Communities (ARIC) study. Circulation 1998; 98:204-210.

4 Perry IJ, Wannamethee SG, Whincup PH, Shaper AG, Walker MK, Alberti KG. Serum insulin and incident coronary heart disease in middle-aged British men. Am J Epidemiol 1996; 144:224-234.

5 Falk E, Shah PK, Fuster V. Coronary plaque disruption. Circulation 1995; 92:657-671.

6 Hong MK, Mintz GS, Lee CW, Kim YH, Lee SW, Song JM. Comparison of coronary plaque rupture between stable angina and acute myocardial infarction: a three-vessel intravascular ultrasound study in 235 patients. Circulation 2004; 110:928-933.

7 Yano K, Reed DM, McGee DL. Ten-year incidence of coronary heart disease in the Honolulu Heart Program. Relationship to biologic and lifestyle characteristics. Am J Epidemiol 1984; 119:653-666.

8 Hagman M, Wilhelmsen L, Wedel H, Pennert K. Risk factors for angina pectoris in a population study of Swedish men. J Chron Dis 1987; 40:265-275.

9 Dunder K, Lind L, Lagerqvist B, Zethelius B, Vessby B, Lithell H. Cardiovascular risk factors for stable angina pectoris versus unheralded myocardial infarction. Am Heart J 2004; 147:502-508.

10 Ducimetiere P, Ruidavets JB, Montaye M, Haas B, Yarnell J. Five-year incidence of angina pectoris and other forms of coronary heart disease in healthy men aged 50-59 in France and Northern Ireland: the Prospective Epidemiological Study of Myocardial Infarction (PRIME) Study. Int J Epidemiol 2001; 30:1057-1062.

11 Chambless LE, Heiss G, Shahar E, Earp MJ, Toole J. Prediction of ischemic stroke risk in the Atherosclerosis Risk in Communities Study. Am J Epidemiol 2004; 160:259-269.

12 Nielsen KM, Foldspang A, Larsen ML, Gerdes LU, Rasmussen S, Faergeman O. Estimating the incidence of the acute coronary syndrome: data from a Danish cohort of 138290 persons. Eur J Cardiovasc Prev Rehabil 2007; 14:608-614.

13 Hemingway $\mathrm{H}$, McCallum A, Shipley M, Manderbacka K, Martikainen P, Keskimäki I. Incidence and prognostic implications of stable angina pectoris among women and men. JAMA 2006; 295:1404-1411.

14 Rosengren A, Wallentin L, Simoons M, Gitt AK, Behar S, Battler A. Cardiovascular risk factors and clinical presentation in acute coronary syndromes. Heart 2005; 91:1141-1147.

15 Ambrose JA, Barua RJ. The Pathophysiology of cigarette smoking and cardiovascular disease. An update. J Am Coll Cardiol 2004; 43: 1731-1737.

16 Simpson AJ, Gray RS, Moore NR, Booth NA. The effects of chronic smoking on the fibrinolytic potential of plasma and platelets. Br J Haematol 1997; 97:208-213.

17 Baguet JP, Barone-Rochette G, Malion JM. European Society of Hypertension Newsletter: hypertension and coronary heart disease. J Hypertens 2006; 24:2323-2325.

18 Lee RT, Grodzinsky AJ, Frank EH, Kamm RD, Schoen FJ. Structuredependant dynamicmechanical behaviour of fibrous caps from human atherosclerotic plaques. Circulation 1991; 83:1764-1770.

19 Sjögren LS, Doroudi R, Gan L, Jungersten L, Hrafnkelsdottir T, Jern S. Elevated intraluminal pressure inhibits vascular tissue plasminogen activator secretion and downregulates its gene expression. Hypertension 2000; 35:1002-1008.

20 Benetos A, Safar M, Rudnichi A, Smulyan H, Richard JL, Ducimetiere P. Pulse pressure: a predictor of long-term cardiovascular mortality in a French male population. Hypertension 1997; 30:1410-1415.

21 Franklin SS, Khan SA, Wong ND, Larson MG, Levy D. Is pulse pressure useful in predicting risk for coronary heart disease, The Framingham Heart Study. Circulation 1999; 100:354-360.

22 Madhavan S, Ooi WL, Cohen H, Alderman MH. Relation of pulse pressure and blood pressure reduction to the incidence of myocardial infarction. Hypertension 1994; 23:395-401.

23 Go AS, Iribarren C, Chandra M, Lathon PV, Fortmann SP, Quertermous T. Statin and beta-blocker therapy and the initial presentation of coronary heart disease. Ann Intern Med 2006; 144:229-238.

24 Lundblad D, Holmgren L, Janssen JH, Naslund U, Eliasson M. Gender differences in trends of acute myocardial infarction events: the Northern Sweden MONICA study 1985-2004. BMC Cardiovasc Disord 2008; 8:17.

25 Hardoon SL, Whincup PH, Lennon LT, Wannamethee SG, Capewell S, Morris RW. How much of the recent decline in the incidence of myocardial infarction in British men can be explained by changes in cardiovascular risk factors? Evidence from a prospective population-based study. Circulation 2008; 117:598-604. 